\title{
High Performance Liquid Chromatography Method for the Determination of Anethole in Rat Plasma
}

\author{
Vinicius HV Fagundes ${ }^{1}$, Rilson J Pinho ${ }^{1}$, Luiz AM Wiirzler ${ }^{1}$, Elza Kimura ${ }^{2}$, \\ Ciomar A Bersani-Amado ${ }^{1}$ and Roberto KN Cuman ${ }^{1}$ \\ ${ }^{1}$ Department of Pharmacology, ${ }^{2}$ Department of Pharmacy, University of Maringá, Avenue Colombo, 5790, Maringa- Brazil
}

*For correspondence: Email: rkncuman@uem.br; Tel: +55 (44) 3011-4923

Received: 12 May 2013

Revised accepted: 13 March 2014

\begin{abstract}
Purpose: To identify and quantify anethole in the essential oil of fruits of Illicium verum Hook (star anise) and in vivo in rat plasma using reverse-phase liquid chromatography.

Methods: Anethole was identified in the essential oil of the fruits of Star anise and determined by gas chromatography-tandem mass spectrometry (GC-MS), nuclear magnetic resonance (NMR), ultraviolet visible spectrophotometry (UV-VIS). A simple, sensitive and validated high performance liguid chromatography (HPLC) technique with UV-VIS detection method was developed for the determination of the compound in rat plasma using: methanol-water $(85: 15, v / v)$ as mobile phase at a flow rate of 0.2 $\mathrm{ml} / \mathrm{min}$ Hypersil ODS Thermo $(150 \mathrm{~mm} \times 2.1 \mathrm{~mm} \times 3.0 \mu \mathrm{M})$ as column with wavelength detection at 259 $n m$.

Results: GC determination showed that anethole in the essential oil of star anise exhibited a retention time of $21.02 \mathrm{~min}$. The validation results for anethole in plasma were satisfactory, with coefficient of determination $\left(R^{2}\right)$ of 0.9945 and relative standard deviation of $<3 \%$. HPLC run time of 4 min with a retention time of $2.73 \mathrm{~min}$ was the faster method to determine anethole when compared to a previously reported method which had a run time of 15 min.

Conclusion: Anethole in the essential oil of Illicium verum Hook can be identified and determined by GC-MS, NMR and UV-VIS, and a superior HPLC method has been developed for the determination of the compound in rat plasma.
\end{abstract}

Keywords: Anethole, High performance liguid chromatography, Star anise, Essential oil, Rat plasma, Illicium verum Hook.

Tropical Journal of Pharmaceutical Research is indexed by Science Citation Index (SciSearch), Scopus, International Pharmaceutical Abstract, Chemical Abstracts, Embase, Index Copernicus, EBSCO, African Index Medicus, JournalSeek, Journal Citation Reports/Science Edition, Directory of Open Access Journals (DOAJ), African Journal Online, Bioline International, Open-J-Gate and Pharmacy Abstracts

\section{INTRODUCTION}

Anethole or trans-anethole (Trans-1-methoxy-4[prop-1-enil] benzene) $[1,2]$ is present as a major component in many essential oils, such as those obtained from star anise (Illicium verum Hook) [1,3], Pimpinella anisum [4], and Foeniculum vulgare [5]. Plants that contain anethole are used in cooking as a condiment and flavoring in alcoholic drinks [2]. Anethole has been utilized in folk medicine because of its soothing and antispasmodic properties [3]. Antiviral activity has been demonstrated for herpes simplex virus type 1 [6], in addition to antimicrobial [4,5] and antifungal [4] activity. The identification and quantification of essential oils are usually performed by gas chromatography (GC) $[2,5,7]$ combined with other techniques $[5,7,8]$ because of the chemical characteristics of these compounds.

In contrast to the majority of papers in the literature that have reported pharmacokinetic profiles obtained using high-performance liquid 
chromatography (HPLC) $[9,10]$, pharmacokinetic studies of 1-8 cineole [11] in the plasma of humans, a compound that is present in many essential oils, such as rosemary [11] and ginger [8], have been conducted using GC. Methodological analysis of substances in plasma are extremely important, and the best method for this type of quantification is HPLC because GC is very time-consuming.

In the scientific literature, several analytical methods for anethole have been described [1, 2 , 12]. For this compound, chromatographic identification, quantification, and analysis, even by HPLC, are time-consuming, making bioavailability studies impractical when the number of samples is large and the total analysis time is prolonged. They are also unviable because of the high use of solvents and high costs.

\section{EXPERIMENTAL}

\section{Acquisition of anethole}

Fruits of star anise (Illicium verum Hook) were collected from the herbarium of medicinal plants of State university of Maringa, Maringa, Brazil, identified and authenticated, by Dr. Maria Serti, a botanist of botanical department of State University of Maringa. A voucher specimen was deposited in the herbarium of State University of Maringa (no. 11612) They were dried and used to obtain the essential oil in which Anethole is present. These fruits were placed in a distillation flask with two outputs in the presence of drag steam distillation using the Clevenger method was then performed. After the essential oil was obtained, it was subjected to steam distillation, with the purpose of obtaining Anethole at the highest purity possible.

\section{Chemicals}

For the HPLC analysis and sample extraction, we used HPLC-grade methanol as the reagent (JT Baker, Phillipsburg, NJ, USA). Deionized water was purified using a Milli-Q water purification system (Millipore, Billerica, MA, USA).

\section{Analysis by NMR and GC-MS}

The chemical composition of the oil was determined by analyzing the nuclear magnetic resonance (NMR) spectra, model Mercury plus BB, (Varian Inc, USA) of carbon $\left({ }^{13} \mathrm{C} ; 75.5 \mathrm{MHz}\right.$ ) and hydrogen $\left({ }^{1} \mathrm{H} ; 300 \mathrm{MHz}\right)$. The solvent used for the dissolution of the samples was deuterated chloroform $\left(\mathrm{CDCl}_{3}\right)$. The chemical shifts are expressed in parts per million, and the coupling constants $(\mathrm{J})$ are expressed in Hertz $(\mathrm{Hz})$. Together the NMR, to determine the purity of Anethole, gas chromatography coupled with mass spectrometry (GC-MS) was performed (Thermo Electron Corporation Focus GC model). GC-MS analysis were performed using a quadrupole mass spectrometer detector, with an impact electron ionization (EI) source operating at $70 \mathrm{eV}$. The identification of the compounds was determined by analyzing and comparing the retention index observed in the chromatogram with the indices described in the literature. The chromatograms of the samples were recorded under the following conditions: DB-5 capillary column ( $30 \mathrm{~m} \times 0.32 \mathrm{~mm}$ I.D., $0.50 \mu \mathrm{m})$, initial column temperature of $250^{\circ} \mathrm{C}$, an initial time of 1 min at $60^{\circ} \mathrm{C}$, ramp heating to $180^{\circ} \mathrm{C}$ at $3^{\circ} \mathrm{C} / \mathrm{min}$, injector temperature of $220^{\circ} \mathrm{C}$, and helium as the carrier gas at constant flow rate of $1.0 \mathrm{ml} / \mathrm{min}$. The injected volume was $1 \mu \mathrm{l}$ of the sample dissolved in acetone (1:10).

\section{UV-VIS spectrum from photodiode array detector}

The HPLC equipment, model Pro Star (Varian Inc, USA), coupled with a photodiode array detector (PDA) was used to determine the optimal wavelength for the analysis of Anethole. This test used the following parameters: methanol-water (86:14) mobile phase at a flow rate of $1.2 \mathrm{ml} / \mathrm{min}$, reverse-phase $\mathrm{C} 18$ column (SGE; $150 \mathrm{~mm} \times 4.6 \mathrm{~mm} \times 5 \mu \mathrm{m}$ ), and a scanning spectrum of $210-400 \mathrm{~nm}$. The volume of the injection was $15 \mu \mathrm{l}$.

\section{Standard solution}

The standard solution was prepared by dissolving the Anethole standard in HPLC-grade methanol to obtain a solution with a $1000 \mu \mathrm{g} / \mathrm{ml}$ concentration and stored at $4^{\circ} \mathrm{C}$.

Animals

The experiments were performed using the plasma of rats that weighed $220-280 \mathrm{~g}$, were fasted from food and water, and were obtained from the central vivarium of the State University of Maringa. The rats were housed at $22 \pm 2{ }^{\circ} \mathrm{C}$ under a $12 \mathrm{~h} / 12 \mathrm{~h}$ light/dark cycle with artificial light. The experimental protocol was approved by the Ethics Committee on Animal Experimentation of the State University of Maringa (CEAE/UEM 066/2010) and was conducted in accordance with the internationally accepted laboratory animal use, care and Guidelines of Institute for Laboratory Animal Research (ILAR) [13]. The blood of the rats was collected in a syringe that contained heparin and centrifuged at 10,000 
rotations per minute (rpm) for $10 \mathrm{~min}$ at room temperature to obtain the plasma.

\section{Sample preparation}

The samples were prepared by spiking blank rat plasma with a standard solution of anethole. Plasma proteins were precipitated by adding 0.3 $\mathrm{ml}$ of cold HPLC-grade methanol. The sample was vigorously homogenized for $2 \mathrm{~min}$ and centrifuged at $10,000 \mathrm{rpm}$ for $10 \mathrm{~min}$ at $4{ }^{\circ} \mathrm{C}$.

\section{Instruments and chromatographic conditions}

The chromatographic system was composed of a high-performance liquid chromatograph, model 2695, with autosampler, (Waters Corp, Milford, MA, USA), UV- VIS detector, model 2487 (Waters Corp., Milford, MA, USA), and Empower One software. In the development of an analytical method for Anethole using HPLC, different mobile phases were used to obtain optimal results. The best method developed used the following parameters: methanol-water (85:15, $\mathrm{v} / \mathrm{v}$ ) mobile phase, $0.2 \mathrm{ml} / \mathrm{min}$ flow rate, Hypersil ODS THERMO column $(150 \mathrm{~mm} \times 2.1 \mathrm{~mm} \times 3.0$ $\mu \mathrm{M}), 259 \mathrm{~nm}$ wavelength, and $25 \mu \mathrm{l}$ injection volume.

\section{Validation of method for the analysis of anethole in plasma}

The validation of the method used several tests recommended by the Brazilian National Agency of Sanitary Surveillance (ANVISA) and U.S. Food and Drug Administration (FDA) $[14,15]$, including specificity, selectivity, linearity, precision, and accuracy. To evaluate the stability of the sample, we performed post-processing, short-term temperature, and freeze-thaw stability tests $[14,15]$.

To evaluate specificity and selectivity, a chromatographic comparison of the standard anethole solution in methanol and contaminantfree rat plasma was conducted. A detectable interference in the chromatogram in the rat plasma blank at the same retention time of Anethole, could not be $>20 \%$ when compared to that peak area of the lower limit of quantification (LLQ) of anethole.

The calibration curves were constructed using quantification with an external standard and in relation to linear regression based on the peak area of anethole in plasma. Seven different concentrations were used $(0.2-3.0 \mu \mathrm{g} / \mathrm{ml})$. The determinations of the linearity of the calibration curves were performed in triplicate and obtained from the peak area in relation to plasma concentrations. Using the linear regression as model, in which a value of $\mathrm{R}^{2}$ greater than 0.99 was expected.

The precision and accuracy of the method were performed at three different analysis. In each one analysis, three concentration of control samples were evaluated (low, medium, and high concentration of anethole in plasma), in quintuplicate, according to ANVISA and FDA recommendations $[14,15]$. The data of precision and accuracy were evaluated by intra-batch and inter-batch. A low quality control (QCL) must be three-fold more than or equal to the LLQ, which has a concentration of $0.2 \mu \mathrm{g} / \mathrm{ml}$. Therefore, a concentration of $0.6 \mu \mathrm{g} / \mathrm{ml}$ was used as the QCL. The medium quality control (QCM) is the average between the low and high quality controls and used a concentration of $1.7 \mu \mathrm{g} / \mathrm{ml}$. The rules define that high quality control $(\mathrm{QCH})$ needs to be between 75 and $90 \%$ of the concentration of the highest point on the calibration curve; therefore, a concentration of $2.7 \mu \mathrm{g} / \mathrm{ml}$ was used.

Precision was expressed as the relative standard deviation (\%RSD), which should be < $15 \%$. Accuracy (\%) was determined as the ratio between the average of the determined concentrations and nominal concentration, with a deviation $<15 \%$.

The extracted samples recoveries were established by comparing the peak area of plasma samples with those direct injections of a standard solution of anethole in methanol at the same concentrations and conditions.

The test of short-term stability, in which the sample remained for $6 \mathrm{~h}$ at room temperature. Post-preparative stability tests were then performed, in which the sample was extracted and injected into the HPLC column 2, 4, 6, 8, 10, 12 , and $24 \mathrm{~h}$ after extraction. Finally, a freezethaw stability test was performed after a first melting cycle, in which a sample curve calibration is prepared and analyzed and another aliquot is frozen and thawed $24 \mathrm{~h}$ later. The results were compared to determine the stability test results.

\section{Plasma anethole determination}

The rats $(n=8)$ were treated by gavage with anethole at $250 \mathrm{mg} / \mathrm{kg}$. Plasma (300 $\mu \mathrm{l})$ was collected from the animal $0 \mathrm{~min}, 15 \mathrm{~min}, 30 \mathrm{~min}$, and $1,2,4,8,12$ and $24 \mathrm{~h}$ after administration. The samples were prepared for subsequent HPLC analysis. 


\section{Statistical analysis}

Statistical analysis, including linear regression, was carried out by ANOVA. To prove the significance of the regression, $F$ - test was employed. The level of significance used was $p<$ 0 or $p<05$ while the software used was Microsoft Office Excel, version 2010.

\section{RESULTS}

\section{GC-MS and NMR spectra}

The chromatogram of the essential oil from star anise (Fig 1) obtained by GC-MS showed that anethole has a retention time of $21.02 \mathrm{~min}$. Identification was made using a single mass spectrum, and the mass found for anethole was $148 \mathrm{mz}$ (Fig 2).

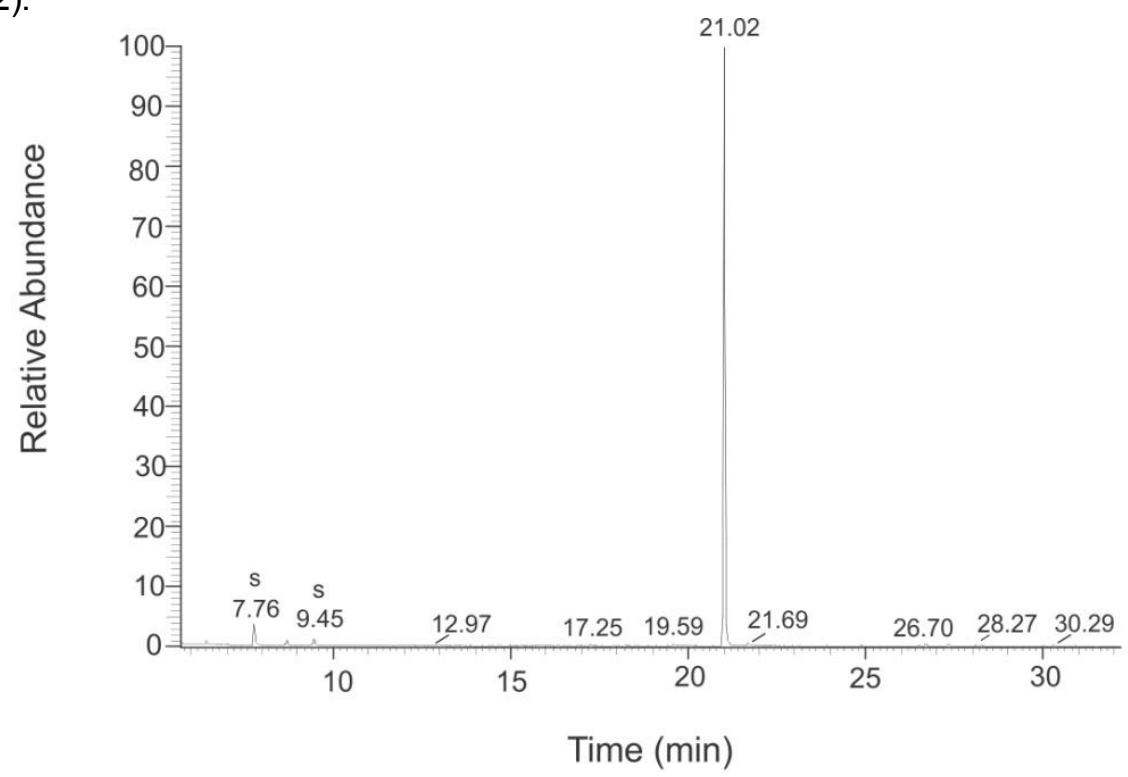

${ }^{1} \mathrm{H}$ and ${ }^{13} \mathrm{C}$ NMR spectra also showed identiified anethole, and just like GC-MS, NMR indicated the presence of some contaminants, but these did not interfere with the identification of the main compound.

NMR ${ }^{1} \mathrm{H}\left(300 \mathrm{MHz} \mathrm{CDCl}_{3}\right): 7.27$ (dt, 2H, H-3 and $\mathrm{H}-5,{ }^{3} \mathrm{~J}_{\mathrm{H}_{3}, \mathrm{H}_{2}}$ and ${ }^{3} \mathrm{~J}_{\mathrm{H}_{5}, \mathrm{H}_{6}}=8.7 \mathrm{~Hz},{ }^{4} \mathrm{~J}_{\mathrm{H}_{3}, \mathrm{H}_{5}}$ and $\left.{ }^{4} \mathrm{~J}_{\mathrm{H}_{5}, \mathrm{H}_{3}}=3.0 \mathrm{~Hz}\right), 6.84(\mathrm{dt}, 2 \mathrm{H}, \mathrm{H}-2$ and $\mathrm{H}-6$, ${ }^{3} \mathrm{~J}_{\mathrm{H}_{2}, \mathrm{H}_{3}}$ and ${ }^{3} \mathrm{~J}_{\mathrm{H}_{6}, \mathrm{H}_{5}}=8.7 \mathrm{~Hz},{ }^{4} \mathrm{~J}_{\mathrm{H}_{2}, \mathrm{H}_{6}}$ and ${ }^{4} \mathrm{~J}_{\mathrm{H}_{6}, \mathrm{H}_{2}}=$ $3.0 \mathrm{~Hz}), 6.35\left(\mathrm{dq}, 1 \mathrm{H}, \mathrm{H}_{\mathrm{a}},{ }^{3} \mathrm{~J}_{\mathrm{H}_{\mathrm{a}}, \mathrm{H}_{\mathrm{b}}}=15.7 \mathrm{~Hz}\right.$, $\left.{ }^{4} \mathrm{~J}_{\mathrm{H}_{\mathrm{a}}, \mathrm{H}_{\mathrm{c}}}=1.6 \mathrm{~Hz}\right), 6.10\left(\mathrm{dq}, 1 \mathrm{H}, \mathrm{H}_{\mathrm{b}},{ }^{3} \mathrm{~J}_{\mathrm{H}_{\mathrm{b}}, \mathrm{H}_{\mathrm{a}}}=15.7\right.$ $\left.\mathrm{Hz},{ }^{3} \mathrm{~J}_{\mathrm{H}_{\mathrm{b}}, \mathrm{H}_{\mathrm{C}}}=6.6 \mathrm{~Hz}\right), 3.79\left(\mathrm{~s}, 3 \mathrm{H}, \mathrm{H}_{\mathrm{d}}\right.$ ), 1.86 (dd, $3 \mathrm{H}, \mathrm{H}_{\mathrm{c}},{ }^{3} \mathrm{~J}_{\mathrm{H}_{\mathrm{c}}, \mathrm{H}_{\mathrm{b}}}=6.5 \mathrm{~Hz},{ }^{4} \mathrm{~J}_{\mathrm{H}_{\mathrm{c}}, \mathrm{H}_{\mathrm{a}}}=1.5 \mathrm{~Hz}$ ).

Fig 1: Chromatogram of the essential oil of Illicium verum Hook obtained by GC-MS; retention time of anethole $=21.02 \mathrm{~min}$

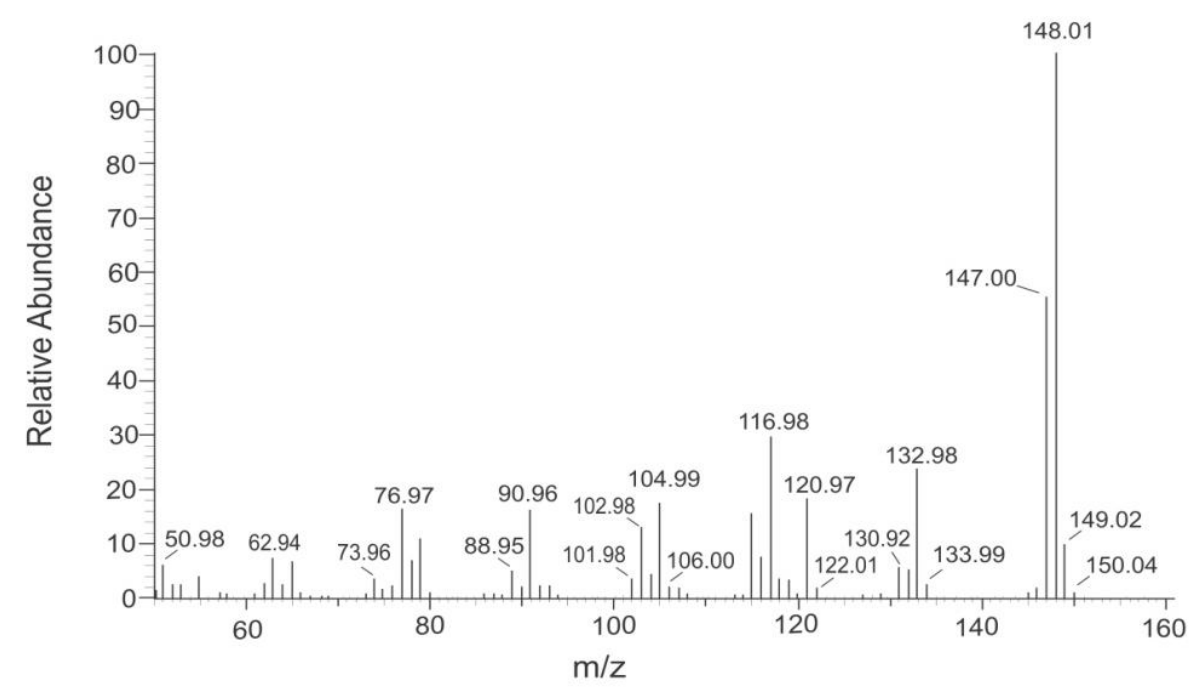

Fig 2: Identification by mass spectra; the mass found for anethole was $148 \mathrm{mz}$ 
Table 1: Precision and accuracy data

\begin{tabular}{lcccc}
\hline Parameter & $\begin{array}{c}\text { Found value } \\
\left(\begin{array}{c}\text { mean } \pm \text { SD, } \\
\boldsymbol{\mu g} / \mathbf{m l})\end{array}\right.\end{array}$ & $\begin{array}{c}\text { Nominal } \\
\text { value } \\
(\boldsymbol{\mu g} / \mathbf{m l})\end{array}$ & Accuracy (\%) & RSD (\%) \\
\hline $\mathrm{QCL}$ & $0.544 \pm 0.005$ & 0.60 & 90.74 & 0.926 \\
$\mathrm{QCM}$ & $1.741 \pm 0.047$ & 1.70 & 102.44 & 2.715 \\
$\mathrm{QCH}$ & $2.786 \pm 0.013$ & 2.70 & 103.21 & 0.486 \\
\hline${ }^{*} \mathrm{LQC}=$ low quality control; ${ }^{* *} M Q C=$ & medium quality control; ${ }^{* * *} H Q C=$ High quality control.
\end{tabular}

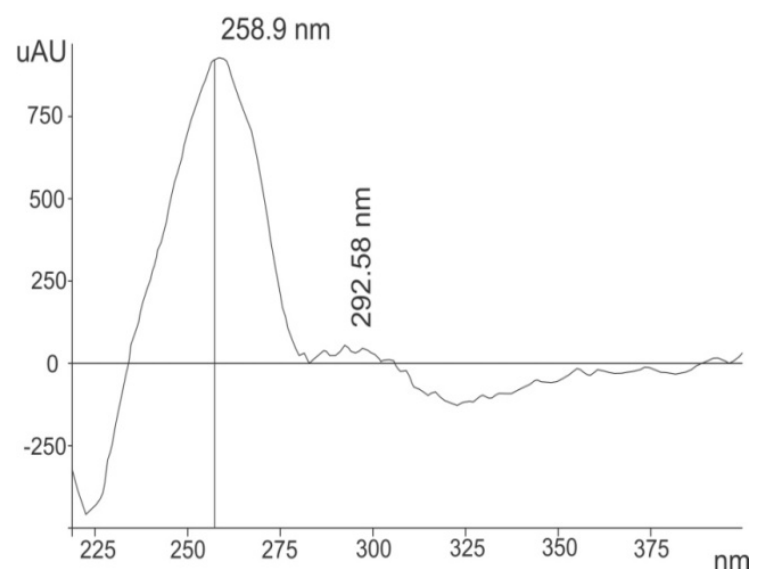

Fig 3: UV-VIS spectrum showing maximum wavelength of absorption for anethole is $259 \mathrm{~nm}$.

NMR ${ }^{13} \mathrm{C}\left(75 \mathrm{MHz}, \mathrm{CDCl}_{3}\right): 158.7$ (C-1), 131.0 (C-4), 130.5 (C-8), 127.0 (C-3 and C-5), 123.6 (C-9), 114.0 (C-2 and C-6), 55.4 (C-7), 18.6 (C10).

The results of GC-MS and NRM show that anethole was the major compound in the essential oil, and the content was approximately $98 \%$.

\section{UV-VIS spectra}

The results show that the optimum wavelength for the analysis of this compound was $259 \mathrm{~nm}$ (Fig 3).

\section{Chromatograms}

The wavelength utilized was $259 \mathrm{~nm}$ [1]. HPLC run time using these parameters was $4 \mathrm{~min}$, with a retention time of $2.73 \mathrm{~min}$.

\section{Extraction efficiency}

The best method for extracting this type of substance is the protein precipitation method, which was very effective and exhibited good performance, with high sample recovery of approximately $96 \%$.

\section{Validation data for anethole in plasma}

No significant interference was found in rat plasma at the same retention time of anethole, proving that endogenous substances did not interfere with the high specificity and selectivity of the method. The calibration curve was linear over the seven points used within the range of 200 to $3000 \mathrm{ng} / \mathrm{ml}$ in plasma. Each point on the curve was obtained from three replicates. The regression equation obtained was $Y=5.379 x+$ 108.300, with regression coefficient $\left(R^{2}\right)=$ $0.9945 . R^{2}$ value was $>0.98$, which is the minimum recommended value for linearity $[14,15]$.

Precision (inter-batch) determination using $\%$ RSD indicate a value $<3 \%$ for three levels of quality control (Table 1); accuracy (inter-batch) was in the range of 90.74 to $103.21 \%$ (Table 1 ). Precision was consistent with reports that assume a maximum deviation of $15 \%$ and standards established for the validation method. Accuracy was also met the standard specifications $[14,15]$.

The test of $6 \mathrm{~h}$ exposure to room temperature showed that the samples showed stability under these conditions, indicating that they could be kept at room temperature during extraction. The post-processing stability of the sample at the initial time (time zero) and $16 \mathrm{~h}$ after extraction showed no no important variations $(p<0,05)$. However, this did not occur $24 \mathrm{~h}$ after extraction when the calibration curve showed no linearity. The samples were considered unstable because significant variation was observed compared with the sample analysis results at time zero and the test of Freeze-thaw stability was performed only once because the sample did not need to be reused during the validation. The results indicated no loss of stability during this cycle.

\section{Anethole profile in vivo}

The results showed that the $\mathrm{C}_{\max }$ of anethole was approximately $1 \mathrm{~h}$ after administration of the substance, and peak concentration was a mean of $2.1 \mathrm{\mu g} / \mathrm{ml}$ of rat plasma (Fig 4). Anethole was 


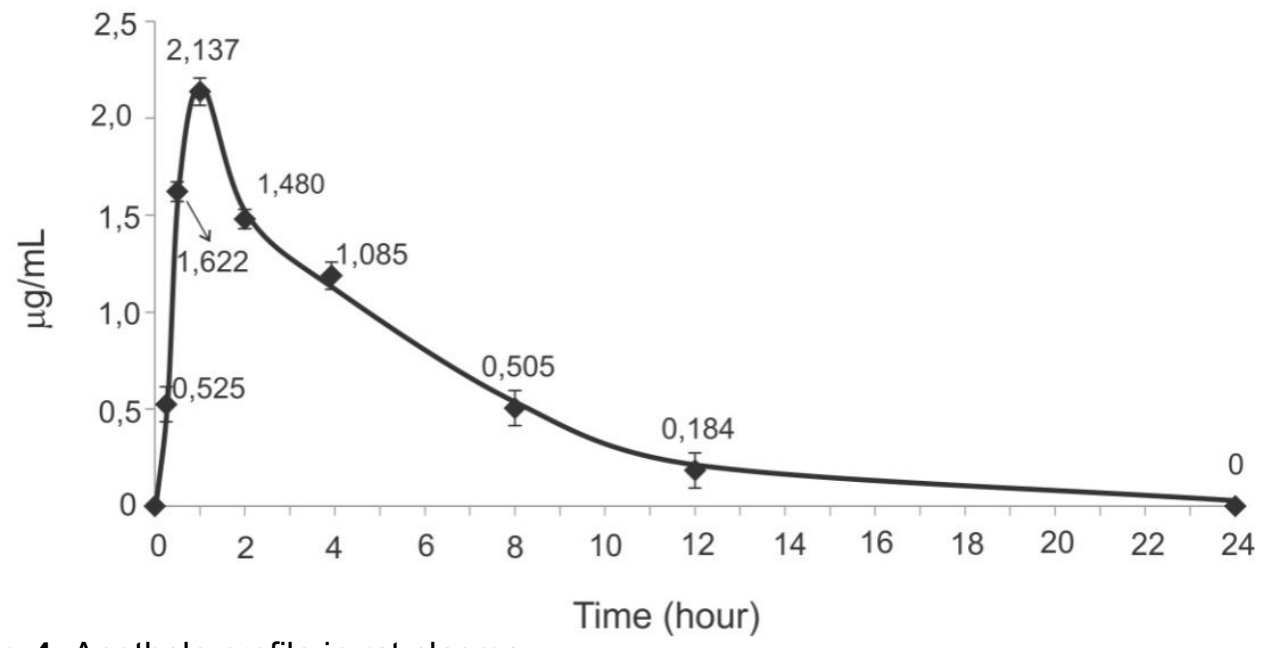

Fig 4: Anethole profile in rat plasma

not detectable in plasma $24 \mathrm{~h}$ after administration.

\section{DISCUSSION}

The mass spectrum of $148 \mathrm{mz}$ was obtained by GC-MS for anethole, and the results of GC-MS and NMR show that anethole is the major compound in the Illicium verum Hook (star anise) star anise oil, approximately $98 \%$, and is consistent with the literature for this substance [16]

A UV-VIS analysis was performed to determine the best wavelength for the analysis and validation of the anethole quantification method. The result found is consistent with literature data $[1,3]$.

The high proportion of methanol in the mobile phase was justified by the fact that Anethole is practically insoluble in water. Therefore, this analytical method for Anethole was faster than the LC method $[1,4]$. In cases of validating large quantities of biological samples, the HPLC method is viable and usually presents very fast analysis time for single substances, in contrast to GC method, which is extremely slow.

The extraction method proposed in this study involved precipitation of the proteins with methanol as the precipitant. Several substances, such as methanol, ethanol, acetonitrile, and perchloric acid, have been shown to be good precipitatants of endogenous substances that can interfere with chromatographic analysis [1718].

Another methodology for the extraction of samples is liquid-liquid extraction using, for example, dichloromethane as the solvent. However, this extraction method is not effective because chromatography with reverse-phase
C18 column was used in the present study, which requires the sample to be dry and resuspended in methanol. Indeed, this method was not feasible in our experiments because anethole is an essential oil and therefore volatile, and would be evaporated when the sample is dried.

An internal standard is desirable, but it was not essential in the present method because the external standard could effectively evaluate the samples prepared in plasma. The present results were considered satisfactory in accordance to references [14,15], without need of an internal standard, similar to another quantitative method in the literature $[19,20]$.

Altogether, the present results indicate that the test had remarkable reproducibility with acceptable accuracy and precision for the parameters determined, as stipulated by FDA FDA [15].

The results obtained from the stability tests indicate that the method is robust and stable. Post-processing stability test of the samples showed that the samples were stable for a long time after extraction and thus could be extracted and stored in the autosampler for long periods of time. Therefore, performing serial extractions and leaving the samples in standby mode in the HPLC are feasible. The test after the first melting cycle was performed according to FDA and ANVISA regulations $[14,15]$. This test becomes important in cases of thawing a sample several times to remove some portions, which may reduce sample stability. Therefore, this test has great importance for stability.

The proposed method using HPLC was effective to determine the pharmacokinetic profile of anethole. Indeed, we can assert that this method 
would be suitable for the analysis of similar drugs, and even in clinical studies of anethole.

\section{CONCLUSION}

The present results indicate that anethole can be identified and determined by GC-MS, NMR, and UV-VIS, and that methanol is a suitable solvent for anethole extraction in plasma. Thus, a simple and sensitive HPLC method has been successfully developed and validated for the determination of anethole in rat plasma.

\section{REFERENCES}

1. Minakshi D, Krishna $D$, Sen $P$, Banerjee AB. Antimicrobial Properties of Star Anise (Illicium verum Hook f). Phytoter Res 2002; 16: 94-95.

2. Jian-hui $Y, X u$-xian $X, K e-l o n g ~ H$. Component analysis of volatile oil from Illicium Verum Hook. J Cent South Univ Technol 2002; 9: 173-176.

3. Ludlow DI, Ragone S, Bruck IS, Bernstein JN, Duchowny $M$, Pena BMG. Neurotoxicities in Infants Seen With the Consumption of Star Anise Tea. Pediatrics 2004; 114.: 653-656

4. Mohammed MJ. Isolation and identification of Anethole from Pimpinella anisum L. fruit oil. An antimicrobial study. J Pharma Res 2009; 915-919.

5. Cetin B, Ozer $H$, Cakir A, Polat $T$, Dursun A, Mete E, Ozturk E, Ekinc M. Antimicrobial Activities of Essential Oil and Hexane Extract of Florence Fennel [Foeniculum vulgare var. azoricum (Mill.) Thell] Against Foodborne Microorganisms. J Med Food 2010; 13: 196-204.

6. Astani A, Reichling J, Schnitzler P. Screening for Antiviral Activities of Isolated Compounds from essential Oils. Evid Based Complement Alternat Med 2009: 1-8.

7. Rattanachaikunsopon $P$, Phumkhachorn P. Antimicrobial activity of basil (Ocimun basilicum) oil against Salmonella enteritidis in vitro and in food. Biosci Biotechnol Biochem 2010; 74: 1200-1204.

8. Carrasco FR, Schmidt G, Romero AL Sartoretto JL, Caparroz-Assef SM, Amado CAB, Cuman RKK. Immunomodulatory activity of Zingiber officinale Roscoe, Salvia officinalis $L$. and Syzygium aromaticum L. essential oils: evidence for humorand cell-mediated responses. J Pharm Pharmacol 2009; 61: 961-967.

9. A. Payasi A, Chaudhary M, Gupta A, Dwivedi VK. Bhatnagar A. Pharmacokinetic study of Sulfobactomax. J Toxicol Sci 2010; 35: 459-464.

10. Mei Y, Xu J, Zhao J, Feng N, Liu Y, Wei L. An HPLC method for determination of oridonin in rabbits using isopsoralen as an internal standard and its application to pharmacokinetic studies fororidoninloaded nanoparticles. J Chromatogr B Anal Technol Biomed Life Sci 2008; 869: 138-141.

11. Jager $W, \mathrm{NaJel} B, \mathrm{NaSel} C$, Binder $R$, Stimpfl $T$, Vycudilik W, Buchbauer G. Pharmacokinetic Studies of the Fragrance Compound 1-8-Cineol in Humans during Inhalation. Chem Senses 1996; 21: 477-480.

12. Bilia AR, Fumarola M, Gallori S, Mazzi G, Vincieri FF. Identification by HPLC-DAD and HPLC-MS Analysis and Quantification of Constituents of Fennel Teas and Decoctions. J Agric Food Chem 2000; 48: 4734-4738.

13. Institute for Laboratory Animal Research (ILAR). Guide for the Care and Use of Laboratory Animals. National Academy Press, Washington, D.IC, 1996.

14. Resolution no. 899: Guide for the Validation of Analytical and Bioanalytical Method. National Agency of Sanitary Surveillance (ANVISA), Brazil 2003.

15. Guidance for industry- Bioanalytical method validation. Food and Drug administration (FDA), USA, 2001.

16. Marquez CA, Wang H, Fabbretti F, Metzger JO. ElectronTransfer-Catalyzed Dimerization of trans-Anethole: Detection of the Distonic Tetramethylene Radical Cation Intermediate by Extractive Electrospray Ionization Mass Spectrometry. J Am Chem Soc 2008; 130: 17208-17209.

17. Billups J, Jones C, Jackson TL, Ablordeppeyc SY, Spencer SD, Simultaneous RP-HPLC-DAD quantification of bromocriptine, haloperidol and its diazepane structural analog in rat plasma with droperidol as internal standard for application to drug-interaction pharmacokinetics. Biomed Chromatogr 2010; 24: 699-705.

18. Zhao $Y$, Wang $X$, Zhao $Y$, Gao X, BI K, Yu Z. HPLC Determination and Pharmacokinetic Study of Homoeriodictyol-7- O-b -D-glucopyranoside in Rat Plasma and Tissues. Biol Pharm Bull 2007; 30: 617-620.

19. Wu $C$, Sheng $Y$, Zhang1 $Y$,. Zhang J, Guo $B$. Identification and characterization of active compounds and their metabolites by highperformance liquid chromatography/Fourier transform ion cyclotron resonance mass spectrometry after oral administration of a herbal extract of Epimedium koreanum Nakai to rats. Rapid Commun Mass Spectrom 2008; 22: 28132824.

20 J. Shen, C. Yang, C. Wu, P. Feng, Z. Wang, Y. Li , Y. Li, $S$. Zhang, Identification of the major metabolites of quinocetone in swine urine using ultra-performance liquid chromatography/electrospray ionization quadrupole time-of-flight tandem mass spectrometry. Rapid Commun Mass Spectrom 2010; 24: 375-383. 